\title{
Nucleophile- or Light-Induced Synthesis of 3-Substituted Phthalides from 2-Formylarylketones
}

2012

Vol. 14, No. 9

2338-2341

\author{
Dario C. Gerbino, Daniel Augner, Nikolay Slavov, and Hans-Günther Schmalz* \\ Department of Chemistry, University of Cologne, Greinstr. 4, 50939 Köln, Germany
}

schmalz@uni-koeln.de

Received March 23, 2012

\section{ABSTRACT}

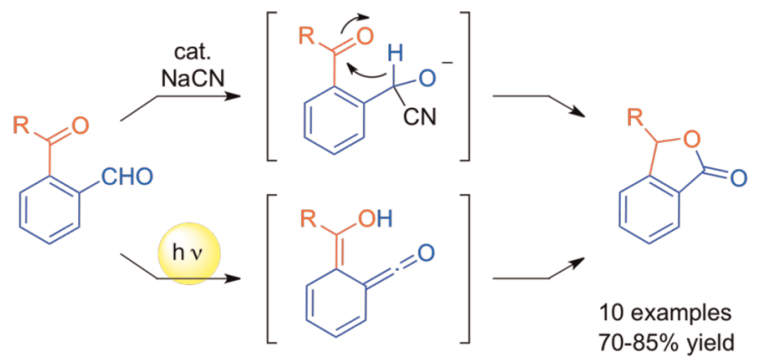

The surprisingly facile conversion (isomerization) of 2-formyl-arylketones into 3-substituted phthalides, as observed for the marine natural product pestalone and its per-0-methylated derivative, was investigated using a series of simple 2-acylbenzaldehydes as substrates. The transformation generally proceeds smoothly in DMSO, either in a Cannizarro-Tishchenko-type reaction under nucleophile catalysis (NaCN) or under photochemical conditions (DMSO, $350 \mathrm{~nm}$ ).

Phthalides, i.e. 1(3H)-isobenzofuran-1-ones, represent a relevant class of compounds because this structural motif is found in a large number of natural products, ${ }^{1}$ synthetic pharmaceuticals, ${ }^{2}$ and building blocks for the synthesis of more complex molecules. ${ }^{3}$ Of particular importance are C3substituted phthalides as exemplified by the natural products cytosporone E (1), ${ }^{4 \mathrm{a}}$ fuscinarin (2), ${ }^{4 \mathrm{~b}}$ isopestacin (3), ${ }^{4 \mathrm{c}}$ and cryphonectric acid (4) ${ }^{4 \mathrm{~d}}$ (Figure 1). Not surprisingly, a

(1) Devon, T. K.; Scott, A. I. Handbook of Naturally Occurring Compounds; Academic Press: New York, 1975; Vol. 1, pp 249-264.

(2) (a) Knepper, K.; Ziegert, R. E.; Bräse, S. T. Tetrahedron 2004, 60, 8591-8603 and references therein. (b) Hung, T. V.; Mooney, B. A.; Prager, R. H.; Tippett, J. M. Aust. J. Chem. 1981, 34, 383-395.

(3) (a) Patil, L.; Borate, H. B.; Ponde, D. E.; Deshpande, V. H. Tetrahedron 2002, 58, 6615-6620. (b) Mal, D.; Pahari, P. Chem. Rev. 2007, 107, 1893-1918.

(4) (a) Brady, S. F.; Wagenaar, M. M.; Singh, M. P.; Janso, J. E.; Clardy, J. Org. Lett. 2000, 2, 4043-4046. (b) Yoganathan, K.; Rossant, C.; Ng, S.; Huang, Y.; Butler, M. S.; Buss, A. D. J. Nat. Prod. 2003, 66, 1116-1117. (c) Strobel, G.; Ford, E.; Worapong, J.; Harper, J. K.; Arif, A. M.; Grant, D. M.; Fung, P. C. W.; Chau, R. M. W. Phytochemistry 2002, 60, 179-183. (d) Arnone, A.; Assante, G.; Nasini, G.; Strada, S.; Vercesi, A. J. Nat. Prod. 2002, 65, 48-50.

(5) For recent examples, see: (a) Mangas-Sanchez, J.; Busto, E.; Gotor-Fernandez, V.; Gotor, V. Org. Lett. 2012, 14, 1444-1447. (b) Yadav, J. S.; Sreenivas, M.; Reddy, A. S.; Reddy, B. V. S. J. Org. Chem. 2010, 75, 8307-8310. (c) Kuriyama, M.; Ishiyama, N.; Shimazawa, R.; Shirai, R.; Onomura, O. J. Org. Chem. 2009, 74, 9210-9213. (d) Zhang, B.; Xu, M. H.; Lin, G. Q. Org. Lett. 2009, 11, 4712-4715. number of methods for the synthesis of 3-substituted phthalides have been developed, most of them exploiting either the cylization of an 1-hydroxyalkyl-substituted benzoic acid derivative $^{5}$ or the alkylation of a preformed phthalide in the 3-position. ${ }^{6}$ Other established methods are based on the carbonylative or carboxylative ortho-functionalization of benzylic alcohols. ${ }^{7}$ In recent years, several new transition-metal-catalyzed phthalide syntheses such as the Pdor Rh-catalyzed reaction of phthalaldehyde with arylboron reagents, ${ }^{8}$ the $\mathrm{Ru}$-catalyzed cross-dehydrogenative $\mathrm{C}-\mathrm{H}$ bond alkenylation of benzoic acids, ${ }^{9}$ or the $\mathrm{Ru}-$ or $\mathrm{Rh}$ catalyzed intramolecular hydroacylation of 2-acylylbenzaldehydes ${ }^{10}$ have been developed.

(6) See, for instance: Singh, M.; Argade, N. P. J. Org. Chem. 2010, 75, 3121-3124.

(7) (a) Cowell, A.; Stille, J. K. J. Am. Chem. Soc. 1980, 102, 41934198. (b) Larock, R. C.; Fellows, C. J. Am. Chem. Soc. 1982, 104, 19001907. (c) Paleo, M. R.; Lamas, C.; Castedo, L.; Dominguez, D. J. Org. Chem. 1992, 57, 2029-2033.

(8) (a) Ye, Z.; Lv, G.; Wang, W.; Zhang, M.; Cheng, J. Angew. Chem., Int. Ed. 2010, 49, 3671-3674. (b) Luo, F.; Pan, S.; Pan, C.; Qian, P.; Cheng, J. Adv. Synth. Catal. 2011, 353, 320-32.

(9) Ackermann, L.; Pospech, J. Org. Lett. 2011, 13, 4153-4155.

(10) (a) Phan, D.; Kim, B.; Dong, V. M. J. Am. Chem. Soc. 2009, 131, 15608-15609. (b) Omura, S.; Fukuyama, T.; Murakami, Y.; Okamoto, H.; Ryu, I. Chem. Commun. 2009, 6741-6743. See also: (c) Willis, M. C. Angew. Chem., Int. Ed. 2010, 49, 6026-6027. 

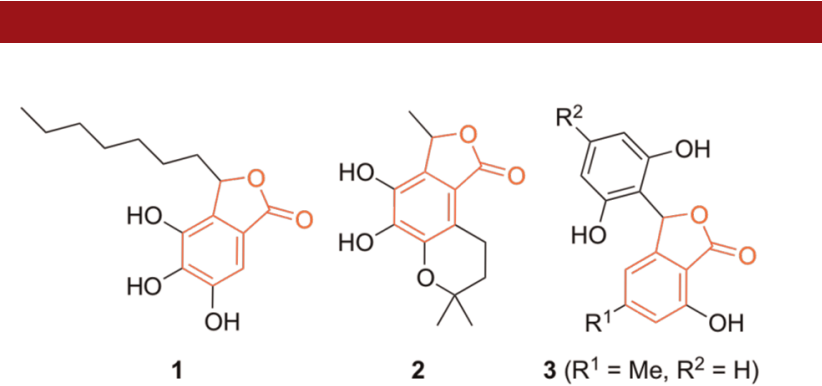

$3\left(\mathrm{R}^{1}=\mathrm{Me}, \mathrm{R}^{2}=\mathrm{H}\right)$

$4\left(\mathrm{R}^{1}=\mathrm{OH}, \mathrm{R}^{2}=\mathrm{CO}_{2} \mathrm{H}\right)$

Figure 1. Selected phthalide natural products.

In the course of our recent synthesis of the marine antibiotic pestalone (5a) ${ }^{11}$ we observed a surprising tendency of the permethylated analog $\mathbf{5 b}$ to isomerize (disproportionate) to the 3-arylphthalide rac-6b, for instance on treatment with LiSEt as a nucleophilic reagent (usually used for the cleavage of methyl aryl ethers). ${ }^{12}$ We also found that $\mathbf{5 a}$ is cleanly converted into pestalalactone (rac-6a) by simple irradiation of a DMSO solution with UV light at $350 \mathrm{~nm}$ (Scheme 1).

Scheme 1. Facile Isomerization of Pestalone (5a) and Its Permethylated Derivative $\mathbf{5 b}$ to Phthalides of Type rac-6 under the Action of UV Light or LiSEt (As a Nucleophile)
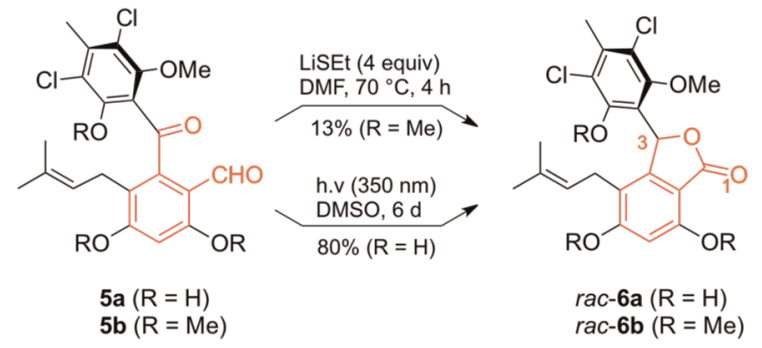

The surprising tendency of $\mathbf{5} \mathbf{a} / \mathbf{b}$ to convert to the corresponding phthalides under different conditions prompted us to probe the generality of this type of transformation using a set of 2-acylbenzaldehydes (7), which were readily prepared as described before ${ }^{13}$ following the procedure of Kotali. $^{14}$

At first, we studied the nucleophile-induced phthalide formation starting from 2-formylbenzophenone (7a) as a model substrate. We found that catalytic amounts (10 mol \%) of a nucleophile are sufficient to achieve the desired transformation. As the results shown in Table 1

(11) (a) Slavov, N.; Cvengros, J.; Neudörfl, J.-M.; Schmalz, H.-G. Angew. Chem., Int. Ed. 2010, 49, 7588-7591. (b) For the isolation and structure elucidation of 5a, see: (b) Cueto, M.; Jensen, P. R.; Kauffman, C.; Fenical, W.; Lobkovsky, E.; Clardy, J. J. Nat. Prod. 2001, 64, 1444 1446.

(12) Cvengros, J.; Neufeind, S.; Becker, A.; Schmalz, H. G. Synlett 2008, 1993-1998.

(13) Augner, D.; Gerbino, D. C.; Neudörfl, J.-M.; Schmalz, H.-G. Org. Lett. 2011, 13, 5374-5377.

(14) (a) Kotali, A.; Papapetrou, M.; Dimos, V.; Harris, P. Org. Prep. Proc. Int. 1998, 30, 177-181. (b) Kotali, A.; Tsoungas, P. G. Tetrahedron Lett. 1987, 28, 4321-4322. (c) Jacq, J.; Einhorn, C.; Einhorn, J. Org. Lett. 2008, 10, 3757-3760. reveal, we identified $\mathrm{NaCN}$ as a convenient and inexpensive nucleophilic catalyst that is more effective than the originally employed LiSEt. Also, DMSO gave better results in comparison to DMF. Under the optimized conditions $\left(10 \mathrm{~mol} \% \mathrm{NaCN}, \mathrm{DMSO}, 4 \mathrm{~h}, 50^{\circ} \mathrm{C}\right)$ the reaction of $7 \mathbf{a}$ proceeded smoothly to afford pure rac-8a in $70 \%$ isolated yield after chromatography.

Table 1. Optimization of the Reaction Conditions ${ }^{a}$
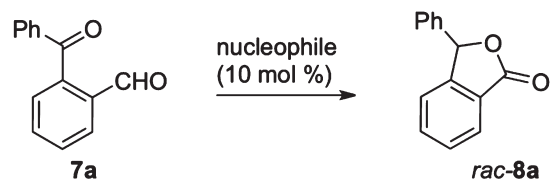

\begin{tabular}{cclrr}
\hline entry & nucleophile & solvent & temp & yield $^{b}$ \\
\hline 1 & LiSEt & DMF & 25 & $32 \%$ \\
2 & LiSEt & DMSO & 25 & $35 \%$ \\
3 & LiSEt & DMSO & 50 & $39 \%$ \\
4 & LiSEt & DMSO & 100 & $39 \%$ \\
5 & NaCN & DMF & 50 & $45 \%$ \\
$\mathbf{6}$ & NaCN & DMSO & $\mathbf{5 0}$ & $\mathbf{7 0 \%}$ \\
7 & NaCN & DMSO & 100 & $60 \%$
\end{tabular}

${ }^{a}$ Conditions: substrate $7 \mathbf{a}(0.5 \mathrm{mmol})$ and nucleophile $(10 \mathrm{~mol} \%)$ in dry solvent $(1.5 \mathrm{~mL}), 4 \mathrm{~h}$, under argon. ${ }^{b}$ Isolated yield.

The scope and the general efficiency of the method was then demonstrated by reacting a set of nine different orthoacylbenzaldehydes under the optimized conditions. The results shown in Table 2 show that the protocol tolerates a range of functional groups, including nitro-phenyl, pyridyl, bromophenyl, anisyl, and a free phenolic $\mathrm{OH}$ function. The electronic properties of the substituent at the central arene unit of the substrates (7) had little effect on the reaction yield.

Mechanistically, we assume that the nucleophile-catalyzed transformation follows a Cannizzaro-Tishchenkotype pathway ${ }^{11 a, 15}$ involving a primary attack of the nucleophilic catalyst at the aldehyde function of the substrate 7 (Scheme 2). The resulting intermediate 9 then undergoes an intramolecular hydride transfer (disproportionation) to form an alkoxide intermediate (10). In the final step, the lactone ring is established through a 5-exotrig attack of the alkoxide at the carbonyl function under release of the nucleophilic catalyst. ${ }^{16}$

In the second part of the study, we investigated the lightinduced isomerization of ortho-formyl-arylketones using the same set of substrates $(\mathbf{7} \mathbf{a}-\mathbf{i})$. And indeed, on irradiation of a DMSO solution with UV light $(350 \mathrm{~nm})$ for 3

(15) (a) Cannizzaro, S. Justus Liebigs Ann. Chem. 1853, 88, 129. (b) Tishchenko, V. E. J. Russ. Phys. Chem. Soc. 1906, 38, 355-418. For a review, see: (c) Törrmäkangas, O. P.; Koskinen, A. M. P. Recent Res. Dev. Org. Chem. 2001, 225-255. See also: (d) Cronin, L.; Manoni, F.; Connor, C. J. O.; Connon, S. J. Angew. Chem., Int. Ed. 2010, 49, 30453048.

(16) For the formation of phthalides from phthalaldehyde under solid-base catalysis, see: (a) Seki, T.; Tachikawa, H.; Yamada, T.; Hattori, H. J. Catal. 2003, 217, 117-126. For a mechanistically related reaction mediated by a $N$-heterocyclic carbene, see: (b) Chan, A.; Scheidt, K. A. J. Am. Chem. Soc. 2006, 128, 4558-4559. 
Scheme 2. Nucleophile-Induced Conversion of 2-Formyl-arylketones (7) to Phthalides (8) through a Cannizar-

ro-Tishchenko-Type Mechanism
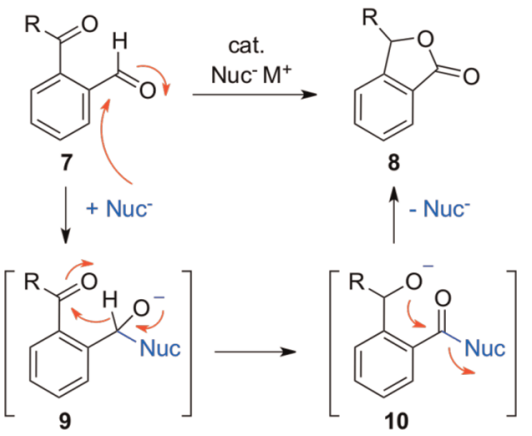

days, all compounds cleanly afforded the corresponding isobenzofuranones $(\mathrm{rac}-\mathbf{8} \mathbf{a}-\mathbf{i})$ in good isolated yields (71-85\%) after chromatographic purification (Table 2). By performing the photolysis experiments in NMR tubes (employing $d_{6}$-DMSO) the reaction progress could be monitored by ${ }^{1} \mathrm{H}$ NMR (compare Figure 2) and no intermediate species could be detected this way. A control experiment in the dark ensured the necessity of light to induce the phthalide formation. In all cases, the photochemical protocol gave rise to the phthalide products ( $\mathrm{rac}$ $\mathbf{8 a}-\mathbf{i})$ in slightly higher yields as compared to the $\mathrm{NaCN}-$ catalyzed reactions (Table 2 ).

A plausible mechanism for the light-induced process (Scheme 3) starts with a Norrish II type reaction and a concomitant formation of a photoenol, i.e. an enol-ketene of type 11. ${ }^{17}$ Assumably, this intermediate then cyclizes through intramolecular addition of the $\mathrm{OH}$ function to the ketene to give a 1-hydroxy-isobenzofurane (12) which finally tautomerizes to the more stable phthalide $\mathrm{rac}-\mathbf{8}$.

As mentioned above, the work described herein was triggered by some surprising observations made in the course of our synthesis of pestalone (5a). ${ }^{1 \mathrm{la}}$ Therefore, we were in the position to probe the developed protocols once more using a sample of synthetic 5a. To our satisfaction, treatment of 5a with $10 \mathrm{~mol} \%$ of $\mathrm{NaCN}$ in DMSO proceeded smoothly to give pure pestalalactone ( $\mathrm{rac}-\mathbf{6 a}$ ) in $62 \%$ yield after recrystallization (Scheme 4$).{ }^{18}$

The photochemical isomerization of 5a into rac-6a was carefully monitored by means of ${ }^{1} \mathrm{H}$ NMR spectroscopy. Figure 1 shows the very clean conversion as indicated, for instance, by the disappearance/reappearance of the olefinic signal $\left(\mathrm{H}_{2}^{\prime}\right)$. An interesting observation is the doubling of certain signals (e.g., H3 and H5) in the product (rac-6a) as a consequence of a hindered rotation of the 3-aryl substituent on the NMR time scale (generation of atropdiastereomers).

(17) (a) Sato, T.; Tamura, K.; Maruyama, K.; Ogawa, O.; Imamura, T. J. Chem. Soc., Perkin Trans. 1 1976, 779-783. (b) Netto-Ferreira, J. C.; Scaiano, J. C. Can. J. Chem. 1993, 71, 1209-1215. (c) Plistil, L.; Solomek, T.; Wirz, J.; Heger, D.; Klan, P. J. Org. Chem. 2006, 71, 80508058.

(18) The structure of rac-6a was unambiguously proven by X-ray crystallograpy (CCDC 781113).
Table 2. Conversion of Various 2-Acyl-benzaldehydes (7) into the Isomeric Phthalides $(\mathrm{rac}-\mathbf{8})^{a}$

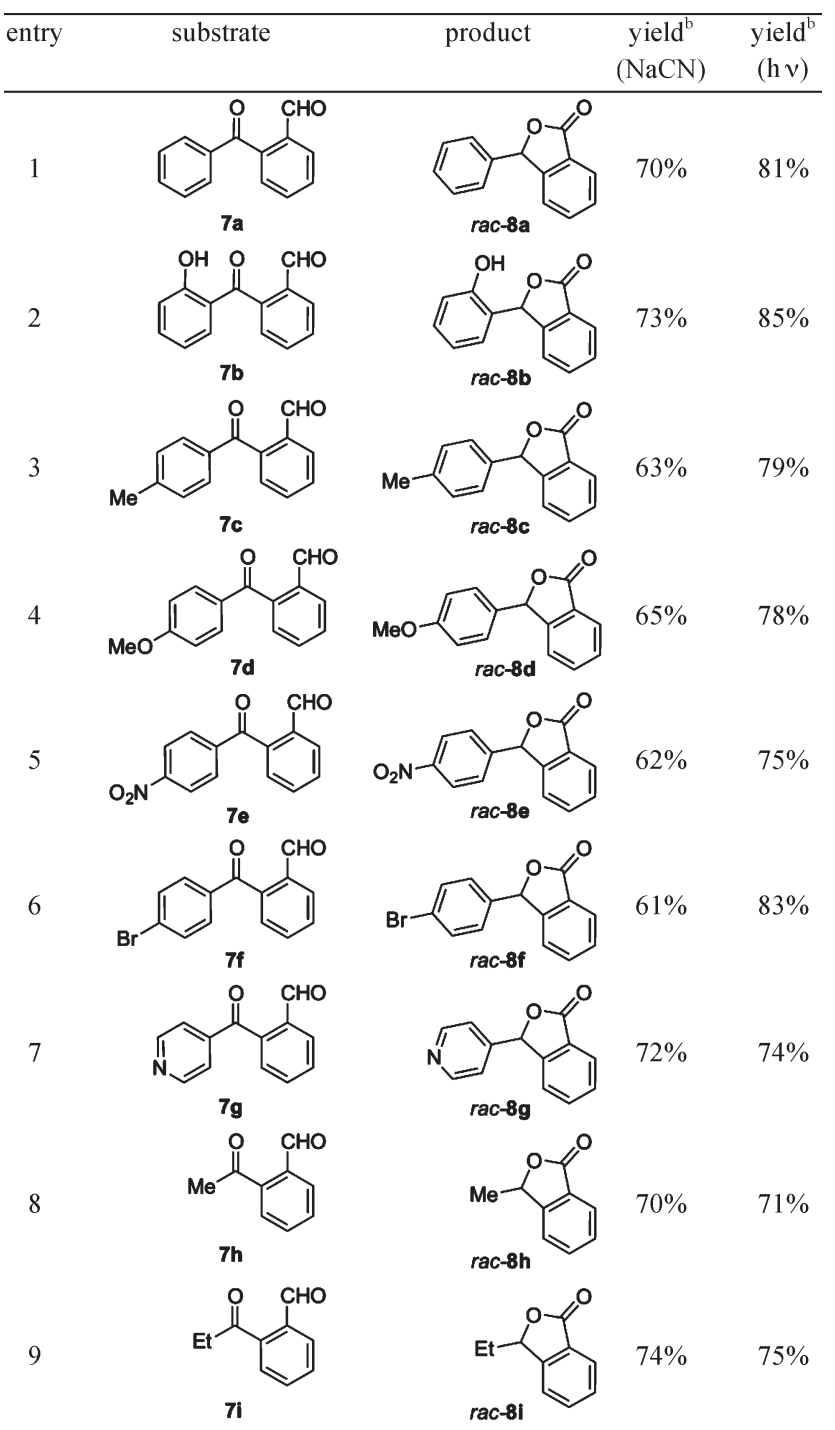

${ }^{a}$ Conditions: $\mathrm{NaCN}(10 \mathrm{~mol} \%)$, DMSO, $50{ }^{\circ} \mathrm{C}, 4 \mathrm{~h}$; or $\mathrm{h} v 35 \mathrm{~nm}$, DMSO, rt, 3 d. ${ }^{b}$ Isolated yield.

Scheme 3. Proposed Mechanism of the Light-Induced Conversion of 2-Formyl-arylketones (7) to Phthalides of Type 8
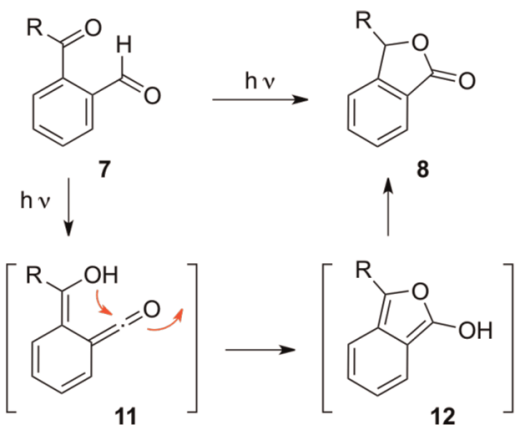

Org. Lett., Vol. 14, No. 9, 2012 
Scheme 4. NaCN-Catalyzed Conversion of Pestalone (5a) into Pestalalactone (rac-6a)
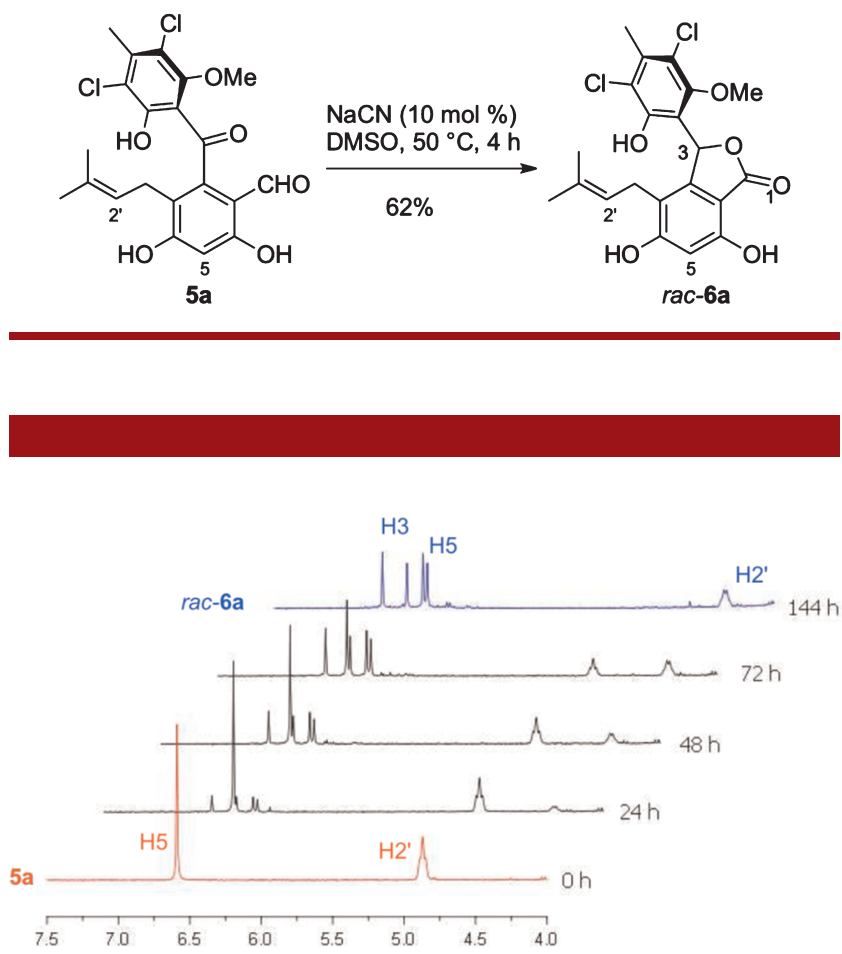

Figure 2. Monitoring the photolysis of 5a by ${ }^{1} \mathrm{H}$ NMR (in $d_{6}$-DMSO).

In conclusion, we have developed two complementary protocols for the nucleophile- or light-induced synthesis of 3-substituted phthalides from 2-formylarylketones under

(19) For other natural products with an ortho-formylbenzophenone substructure, see: (a) Kralj, A.; Kehraus, S.; Krick, A.; Eguereva, E.; Kelter, G.; Maurer, M.; Wortmann, A.; Fiebig, H.-H.; König, G. M. J. Nat. Prod. 2006, 69, 955-1000 (Arugosin H). (b) Hashimoto, T.; Tahara, S.; Takaoka, S.; Tori, M.; Asakawa, Y. Chem. Pharm. Bull. 1994, 42, 1528-1530 (Daldinals A-C). (c) Zhang, C.; Ondeyka, J. G.; Herath, K. B.; Guan, G.; Collado, J.; Platas, G.; Pelaez, F.; Leavitt, P. S.; Gurnett, A.; Nare, B.; Liberator, P.; Singh, S. B. J. Nat. Prod. 2005, 68, 611-613 (Tenellones A+B). (d) Hida, T.; Ishii, T.; Kanamaru, T.; Muroi, M. J. Antibiot. 1991, 44, 600-612 (TAN-931).

(20) Breslow, R. J. Am. Chem. Soc. 1958, 80, 3719-3726.

(21) Compare: (a) Quinkert, G.; Stark, H. Angew. Chem., Int. Ed. Engl. 1983, 22, 637-655. (b) Nicolaou, K. C.; Gray, D.; Tae, J. S. Angew. Chem., Int. Ed. 2001, 40, 3675-3678. mild conditions. The smooth transformations and, in particular, the ease of conversion of 5a into rac-6a even raises the question whether the biosynthesis of natural phthalides ${ }^{4}$ (compare Figure 1) might proceed (at least in certain cases) in a related fashion via ortho-formyl arylketone precursors, ${ }^{19}$ which (in principle) could be isomerized into the corresponding phthalides under the action of a thiamine- (vitamine $\mathrm{B}_{1^{-}}$) derived nucleophilic carbene. ${ }^{16 \mathrm{~b}, 20}$ An interesting aspect of the photochemical method developed is the proposed emergence of an enolketene (11) and an isobenzofuran (12) intermediate, which could possibly be trapped by an appropriate dienophile in a Diels-Alder-type reaction. ${ }^{21}$

The methods described here for the synthesis of phthalides can also be be classified as a redox-neutral interconversion (fusion) of two functional groups. ${ }^{22}$ Due to the mild reaction conditions the methodology may prove of value in the context of the synthesis of more complex and highly functionalized molecules. A remaining challenge, of course, is to render the process enantioselective, for instance by employing chiral nucleophilic catalysts instead of $\mathrm{NaCN}^{23}$

Acknowledgment. This work was supported by the Alexander von Humboldt Foundation (G. Forster postdoctoral fellowship to D.C.G.). We also thank Prof. A. Griesbeck, University of Cologne, for technical support concerning the photochemical transformations.

Supporting Information Available. Detailed experimental procedures, characterization data, and copies of ${ }^{1} \mathrm{H}$ and ${ }^{13} \mathrm{C}$ NMR spectra of all phthalides prepared. This material is available free of charge via the Internet at http://pubs.acs.org. The authors declare no competing financial interest.

(22) (a) Jurberg, I. D.; Peng, B.; Wöstefeld, E.; Wasserloos, M.; Maulide, N. Angew. Chem., Int. Ed. 2012, 51, 1950-1953. (b) Mori, K.; Ehara, K.; Kurihara, K.; Akiyama, T. J. Am. Chem. Soc. 2011, 133, 6166-6169. (c) Haibach, M. C.; Deb, I.; De, C. K.; Seidel, D. J. Am. Chem. Soc. 2011, 133, 2100-2103.

(23) So far, only the Rh-catalyzed intramolecular hydroacylation allows this type of reaction to proceed in an enantioselective fashion (in the presence of a chiral ligand); see ref 10a.

The authors declare no competing financial interest. 